\title{
Dinâmica das fontes de crescimento da produção de leite brasileira entre 2001 e 2012: um enfoque na região de planejamento Corede Produção - RS
}

\author{
Eduardo Belisário Finamore* \\ Cássia Aparecida Pasqual \\ Marco Antonio Montoya***
}

\begin{abstract}
Resumo
O objetivo deste estudo foi analisar as fontes de crescimento da produção de leite em diferentes espaços geográficos brasileiros, enfocando a Região da Produção, no estado do Rio Grande do Sul, no período de 2001 a 2012. Observou-se que, na média, o Brasil, o estado do Rio Grande do Sul e a Região da Produção, tiveram uma expansão da produção leite (de 57,5\%; $82,2 \%$ e $166,6 \%$, respectivamente) explicada em maior parte pela expansão da produtividade (de $25,7 \%$; 44,7\%; e 73,0\%, respectivamente) do que pela expansão do número de vacas ordenhadas (de 25,3\%; 25,9\%; e 54,1\%, respectivamente), com vantagens maiores para a Região da Produção, seguido pelo estado do Rio Grande do Sul. A produtividade média da Região da Produção (4.533 litros/vaca) e da maioria de seus municípios são superiores à produtividade de países exportadores como a Nova Zelândia $(4.099 \mathrm{~kg})$. Entre 2001 e 2012 , a produtividade marginal do Rio Grande do Sul (5.851 litros/vaca) e da Região da Produção (8.070 litros/ vaca) foram superiores à produtividade média da Argentina $(5.326 \mathrm{~kg})$ e da União Europeia $(6.030 \mathrm{~kg})$, respectivamente, sinalizando a produção de geração de excedentes exportáveis com competitividade.
\end{abstract}

Palavras-chave: Fontes de crescimento, produção de leite, produtividade média e marginal.

* Doutor em Economia Aplicada pela Universidade Federal de Viçosa (UFV). Professor da Faculdade de Ciências Econômicas, Administrativas e Contábeis da Universidade de Passo Fundo (UPF).

E-mail: finamore@upf.br

** Mestre em Agronegócios pela Universidade Federal do Rio Grande do Sul. Professora da Faculdade de Ciências Econômicas, Administrativas e Contábeis da Universidade de Passo Fundo. E-mail: cpasqual@upf.br

*** Doutor em Economia Aplicada pela Universidade de São Paulo (USP), Mestre em Economia Rural pela Universidade Federal do Rio Grande do Sul (Ufrgs). Professor da Faculdade de Ciências Econômicas, Administrativas e Contábeis da Universidade de Passo Fundo (UPF).E-mail: montoya@upf.br

http://dx.doi.org/10.5335/rtee.v23i49.8255

Submissão: 23/08/2017. Aceite: 26/10/2017. 


\section{Introdução}

Ao longo do tempo a cadeia láctea brasileira passou por grandes transformações sejam elas originadas de mudanças estruturais da demanda do produto ou da oferta.

As causas tradicionais atribuídas às transformações observadas na cadeia de lácteos brasileira a partir dos anos 1990 foram a desregulamentação do mercado do leite; a estabilização da economia brasileira em decorrência do plano real; e a maior abertura do comércio internacional de lácteos. Esses fatores tiveram como principais efeitos um aumento significativo da produção de leite e uma queda do preço recebido pelo produtor de leite devido a uma grande modernização da produção e ao aumento da competitividade. De outro lado, houve uma tendência à concentração na produção primária do leite, com redução do número de produtores rurais no mercado formal, e na produção industrial, com fusões e aquisições, lideradas por empresas privadas domésticas e internacionais, contando até mesmo com incentivos de recursos públicos.

A tendência concentradora da produção de leite, como revelam os Censos Agropecuários do IBGE, está diretamente relacionada com a economia de escala (redução do custo de produção à medida que aumenta o tamanho da exploração) típica da atividade leiteira.

Uma tendência ainda não definida é se o aumento da produção no Brasil será capaz de gerar excedentes exportáveis com competitividade suficiente para inserir o país no mercado internacional.

Ao observar a balança comercial de produtos lácteos do Brasil (ALICEWeb/ MDIC) o que se verifica é que essa tem sido deficitária nos últimos anos, salientando que esse déficit é pequeno (US\$ 511 milhões em 2012) se comparado ao tamanho do PIB do agronegócio do leite no País ( $\mathrm{R} \$ 42$ bilhões, segundo o Cepea - PIB da cadeia do leite de 2009 a preços de 2012). Em 2012 o Brasil foi exportador líquido de leite UHT, leite condensado, e leite modificado, sendo que estes produtos responderam por $83 \%$ das exportações; e importador líquido de leite em pó e soro de leite, que responderam por $70 \%$ das importações. O País foi também importador líquido de manteigas, queijos e doce de leite com um equilíbrio nas exportações e importações de iogurtes (ALICEWeb/MDIC).

Cabe dizer que os derivados lácteos como iogurtes, queijos, manteigas e doce de leite, transacionados com o exterior, oferecem algum grau de diferenciação e são em sua maioria oriundos da Argentina e do Uruguai, não revelando perda de competividade, pelo contrário revelando ganhos de bem estar ao consumidor com uma 
maior variedade de produtos a sua escolha. Devem ser alvos de um estudo mais aprofundado pelas indústrias nacionais no sentido de obter uma combinação favorável entre qualidade, marketing e inovação, voltado a diferentes grupos de renda, visando aumentar o consumo interno e conquistar consumidores internacionais.

Obviamente, além da diferenciação da produção dos derivados lácteos, para que a produção de leite brasileira alcance excedentes consideráveis para a exportação, mais do que somente atender ao mercado doméstico, é necessário que a produção de leite adquira contornos mais próximos dos verificados em outros países como Nova Zelândia e Estados Unidos, ancorando sua produção em escala e eficiência de custos (CARVALHO, 2007).

Como mostra Gomes (1991), decompondo as fontes de crescimento da produção de leite brasileira, essa pode crescer, aumentando o número de vacas ordenhadas (crescimento extensivo), aumentando a produtividade (crescimento intensivo) e pela combinação dessas duas fontes. Para o autor, o aumento da produtividade é fundamental para o aumento da lucratividade do produtor, além da melhoria dos termos de troca (relação entre preço do produto e preço do fator de produção).

Ressalta-se que os termos de troca flutuam normalmente ora beneficiando o produtor ora reduzindo sua lucratividade e esse fator como depende das condições agregadas de oferta e demanda da economia foge do controle do produtor enquanto gestor de uma propriedade empresarial. Já o aumento da produtividade é uma variável controlável seja pela melhoria da genética das vacas seja pela melhoria da alimentação. Claro o aumento de produtividade nas propriedades leiteiras brasileiras podem receber o incentivo do poder público, seja ele de qualquer esfera, acelerando o processo de desenvolvimento da atividade em questão.

Historicamente, a produtividade do rebanho brasileiro é, em média, uma das mais baixas do mundo. De acordo com o Departamento de Agricultura americano - USDA (2013), em 2012, a produtividade média do Brasil era de $1.582 \mathrm{~kg}$ de leite/ano/vaca ordenhada, enquanto da Nova Zelândia era de $4.099 \mathrm{~kg}$, Argentina 5.3260 kg, União Europeia de 6.030 kg, e Estados Unidos de 9.837 kg. Entretanto, considerando as dimensões continentais do Brasil, a análise da produtividade dos rebanhos leiteiros por estados e regiões que concentram a produção nacional torna-se necessária para entender melhor o crescimento da produção de leite nacional. Em particular no estado do Rio Grande do Sul que, na atualidade, constitui-se no segundo maior produtor de leite no país.

Nesse contexto, este artigo tem como objetivo avaliar, a partir do ano de 2001, as fontes de crescimento e o nível de produtividade da produção de leite no Brasil e no Rio Grande do Sul, enfocando principalmente a região de planejamento 
Corede Produção. Com esses fins, na seção 2, são apresentados os procedimentos metodológicos de decomposição clássica das taxas de crescimento da produção de leite entre tamanho do rebanho e produtividade. Seguidamente, na seção 3, com base na variação da produção, do número de vacas e da produtividade marginal no período de 2001 a 2012, avalia-se a dinâmica do crescimento da produção de leite nos principais estados produtores do país, com o intuito de estabelecer se o incremento da produção se deu por meio das alterações na produtividade ou foi devido a mudanças no tamanho do rebanho ordenhado. Na seção 4, além de avaliar a produtividade marginal, estabelece os excedentes de produção nas regiões de planejamento do Rio Grande do Sul, destacando o Corede Produção e os municípios que o constituem. Finalmente, as principais conclusões obtidas no decorrer das análises são apresentadas na última seção.

\section{Procedimentos metodológicos}

Para avaliar as fontes de crescimento da atividade de produção de leite, utilizou-se o modelo shift-share tradicionalmente empregado em estudos sobre a agropecuária brasileira. $\mathrm{O}$ modelo propõe que a variação da produção da pecuária leiteira, em determinado período, pode ter seu crescimento decomposto em dois efeitos, sendo um, o efeito do aumento da produtividade e outro o efeito da expansão do rebanho. $\mathrm{O}$ efeito-produtividade indica as variações na produção decorrentes do aumento na produtividade em determinado território. É o aumento, na média, do volume de leite produzido por cada animal. Esse efeito decorre principalmente da adoção de novas tecnologias e novas técnicas de produção, ou também de um aumento na qualificação da mão de obra. O efeito-expansão do rebanho representa as variações do volume produzido que são de responsabilidade do maior número de vacas ordenhadas no período.

A expressão final do modelo segue o proposto por Gomes (1991), que parte da igualdade $\mathrm{P}=\frac{\mathrm{P}}{\mathrm{V}} \times \mathrm{V}$, em que $\mathrm{P}=$ produção de leite $\mathrm{e} \mathrm{V}=$ vacas ordenhadas. Após aplicar a derivada logarítmica, obtém-se:

$$
\frac{\Delta \mathrm{P}}{\mathrm{P}}=\frac{\frac{\Delta \mathrm{P}}{\mathrm{P}}}{\overline{\mathrm{V}}}+\frac{\Delta \mathrm{V}}{\mathrm{V}}
$$

Na expressão anterior, a taxa de crescimento da produção $(\Delta P / P)$ é explicada pela soma de dois termos. O primeiro termo à direita do sinal de igualdade 
$(\Delta P / V) /(P / V)$ representa o Efeito Produtividade (EP) e o segundo termo $(\Delta P / V)$ representa o Efeito Expansão do Rebanho, ambos em valores percentuais.

Isso significa que a produção da atividade está relacionada com sua produtividade, o tamanho do rebanho leiteiro e a interação desses dois fatores. Portanto, o aumento ou a redução da produção está condicionado à variação desses fatores.

Filgueiras et al. (2004) avaliaram as fontes de crescimento da cultura de pimenta-do-reino no estado do Pará decompondo a evolução do Valor Bruto da Produção (VBP), nos efeitos: área colhida, rendimento, e preço do produto.

Um ponto a ser avaliado quando a produtividade média está em crescimento é a produtividade marginal. A teoria da produção mostra que quando a produtividade marginal está acima da produtividade média implica que a produtividade média está em crescimento e que, visando atingir o ponto ótimo de eficiência econômica o tomador de decisão deve avançar a produção da unidade produtiva. Implica dizer que quando a produtividade marginal dos insumos variáveis está em crescimento e acima da produtividade média essa ainda não atingiu o seu ponto máximo, limite entre o primeiro e segundo estágio de produção, zona de máximo lucro da unidade produtiva.

Assim, adicionalmente aos indicadores anteriores avalia-se também neste artigo a produtividade marginal, que mede a eficiência produtiva das novas unidades de insumos variáveis (no caso vacas ordenhadas), dada pela seguinte equação $P m g=\frac{\Delta P}{\Delta V}$.

Em conjunto, esses indicadores permitem observar quais fatores tiveram maior importância sobre o crescimento da produção de leite no país, nos estados, nas regiões e nos municípios analisados, entre os anos 2001 e 2012, e em que nível de eficiência se encontra a fronteira atual de produção, com base nas informações municipais agregadas pelo IBGE. Pode-se observar se o aumento da produção foi devido ao simples aumento do número de vacas ou se ao aumento de produtividade, podendo ser uma combinação destes dois fatores observados. Por outro viés, permite inferir acerca da dinâmica do crescimento e sobre o ponto sobre a fronteira de produção da atividade de produção do leite em diferentes espaços regionais.

Sato (1975) observa que na análise de dados agregados, pois, como observa ao contrário das funções de produção micro, a função de produção macro é, depois de tudo, uma entidade fictícia. Não existe um único tomador de decisão macroeconômico que aloca otimamente os recursos ou tente maximizar os lucros coletivamente com base nessa função. Para analisar essa conexão, é preciso levar em conta que as firmas diferem em eficiência produtiva. Se todas fossem idênticas em eficiência, compartilhariam de uma função de produção idêntica. As unidades 
microeconômicas seriam todas homogêneas e não seria necessário distinguir micro e macro: as funções micro poderiam ser somadas para render uma unidade macro e não existiriam problemas de agregação.

Cabe lembrar que as vacas ordenhadas antigas e novas são de diferentes raças, obtidas de diferentes métodos de inseminação, com diferentes potenciais de produtividade que podem ter alcançado o seu limite ou não, dependendo do ambiente em que elas se encontram, da disponibilidade de alimentação, capacidade de gestão, disponibilidade de recursos financeiros, etc. Cabe também salientar que talvez o tamanho do rebanho não tenha se alterado, mas houve descarte de vacas menos produtivas substituídas por vacas mais produtivas (melhoria genética) aumentando a produtividade ou tido melhorias no manejo e na alimentação. Nesse caso poderá ter ocorrido um deslocamento da fronteira de produção devido a melhorias tecnológicas ou se foi devido á parcela menos produtiva das propriedades agrícolas que se aproximaram da fronteira de produção.

Conforme Sato (1975) quanto mais heterogêneas forem as unidades produtivas maiores serão as possibilidades de ganhos de produtividade. A difusão tecnológica, no longo prazo, provoca o deslocamento da escala da fazenda para uma tecnologia superior e leva a firma a ter rendimentos crescentes de escala, chamados de externos à firma. Assim, para analisar mudanças na produção deve-se pensar na função de produção ex ante e ex post.

Função de produção ex ante representa o grupo das técnicas mais avançadas disponíveis. O progresso técnico desloca essa função ex ante. Algumas firmas inovadoras escolhem as técnicas de "melhores práticas" ao longo dessa função e tornam-se, portanto as mais eficientes. As defasagens de adaptação criam as diferenças entre as firmas, municípios e regiões. A função ex ante mostra as melhores combinações de insumos para produzir um dado nível de produto e os produtores têm de escolher uma técnica entre muitas alternativas.

Já funções ex post são de natureza de curto prazo, pois as técnicas são fixas. Uma técnica é caracterizada por uma coleção de bens de capital com certas especificações. Uma vez instalados esses bens, os produtores não podem alterar suas técnicas de produção, a menos que seus bens de capital sejam modificados em suas especificidades ou completamente trocados por outras.

Neste contexto, as análises feitas a seguir são elaboradas com base em dados agregados, que permitem observar as diferenças regionais de eficiência produtiva, apontando para municípios e regiões que adotam as "melhores práticas" de forma individual ou coletiva, podendo ter incentivos tanto privados quanto públicos. 
Essas análises podem ter implicações tanto no desenvolvimento de pesquisa aplicada sobre estimativas de funções de produção, uso e intensidades de uso de fatores de produção, bem como deslocamentos da função de produção por mudanças tecnológicas e ou outros fatores como na elaboração de políticas públicas de desenvolvimento regional bem como definição de regiões que competirão por um mercado global ou que competirão a nível apenas local.

\subsection{Fontes e natureza dos dados}

Os dados utilizados foram extraídos do IBGE (Instituto Brasileiro de Geografia e Estatística), resultados da Pesquisa Pecuária Municipal (PPM) e do Departamento de Agricultura dos Estados Unidos (USDA). A produção de leite no Brasil, levantada pelo IBGE, é medida em litros e nos demais países em $\mathrm{kg}$, cuja fonte é o USDA. O ano de 2001 foi estabelecido para início da análise em função de existir município da região do Corede Produção, foco de estudo, criado no ano de 2001, não havendo dados de anos anteriores. De outro viés fica interessante na medida em que se avalia a dinâmica da produção de leite entre o ano inicial e o ano final do século que se inicia. As estatísticas utilizadas representam as últimas informações disponíveis; portanto, o presente estudo, baseado nas fontes empregadas, tem 0 grau máximo de atualização possível. Podem-se avaliar as fontes de crescimento em períodos intermediários para observar acelerações e desacelerações do crescimento e investigar suas causas. Optou-se em uma comparação da dinâmica espacial no período como um todo.

\section{Fontes de crescimento da produção de leite no Brasil e principais estados produtores}

A Tabela 1 mostra as fontes do crescimento da produção de leite dos 10 principais estados produtores do país, que concentram $87 \%$ da produção nacional, entre os anos 2001 e 2012.

Esse período foi de grandes transformações, pois no início da década o Rio Grande do Sul era o terceiro maior estado produtor de leite do Brasil (atrás de Minas Gerais e de Goiás), passando no final do período para a segunda posição. Esse fato se deve ao maior aumento da produção de leite no Rio Grande do Sul, de 82,2\%, em contrapartida do aumento de $52,7 \%$ em Goiás. Observe-se que a produtividade média do Rio Grande do Sul, em 2012, (2.670 litros/vaca) foi 88\% maior do que a do Brasil (1.417 litros/vaca) e 103\% maior do que a de Goiás (1.317 litros/vaca). 
Tabela 1 - Fontes de crescimento da produção de leite - Brasil e principais estados produtores

\begin{tabular}{|c|c|c|c|c|c|c|c|c|c|}
\hline \multirow{3}{*}{$\begin{array}{c}\text { Brasil e Unidades } \\
\text { da Federação }\end{array}$} & \multirow{2}{*}{\multicolumn{2}{|c|}{$\begin{array}{l}\text { Produção } \\
\text { (1.000 litros) }\end{array}$}} & \multirow{2}{*}{\multicolumn{2}{|c|}{$\begin{array}{l}\text { Vacas Ordenhadas } \\
\text { (cabeças) }\end{array}$}} & \multirow{2}{*}{\multicolumn{2}{|c|}{ Produtividade }} & \multirow{3}{*}{$\begin{array}{c}\text { Variação } \\
\text { Produção }\end{array}$} & \multirow{3}{*}{$\begin{array}{c}\text { Variação } \\
\text { Vacas } \\
\%\end{array}$} & \multirow{3}{*}{$\begin{array}{c}\text { Variação } \\
\text { Produti- } \\
\text { vidade }\end{array}$} \\
\hline & & & & & & & & & \\
\hline & 2001 & 2012 & 2001 & 2012 & 2001 & 2012 & & & \\
\hline Brasil & 20.509 .953 & 32.304 .421 & 18.193 .951 & 22.803 .519 & 1.127 & 1.417 & $57,5 \%$ & $25,3 \%$ & $25,7 \%$ \\
\hline Minas Gerais & 5.981 .223 & 8.905 .984 & 4.474 .638 & 5.674 .293 & 1.337 & 1.570 & $48,9 \%$ & $26,8 \%$ & $17,4 \%$ \\
\hline Rio Grande do Sul & 2.222 .054 & 4.049 .487 & 1.204 .371 & 1.516 .689 & 1.845 & 2.670 & $82,2 \%$ & $25,9 \%$ & $44,7 \%$ \\
\hline Paraná & 1.889 .627 & 3.968 .506 & 1.150 .617 & 1.615 .916 & 1.642 & 2.456 & $110,0 \%$ & $40,4 \%$ & $49,5 \%$ \\
\hline Goiás & 2.321 .740 & 3.546 .329 & 2.121 .271 & 2.692 .841 & 1.095 & 1.317 & $52,7 \%$ & $26,9 \%$ & $20,3 \%$ \\
\hline Santa Catarina & 1.076 .084 & 2.717 .651 & 598.637 & 1.078 .118 & 1.798 & 2.521 & $152,6 \%$ & $80,1 \%$ & $40,2 \%$ \\
\hline São Paulo & 1.783 .017 & 1.689 .715 & 1.732 .129 & 1.469 .829 & 1.029 & 1.150 & $-5,2 \%$ & $-15,1 \%$ & $11,7 \%$ \\
\hline Bahia & 739.099 & 1.079 .097 & 1.522 .242 & 1.943 .015 & 486 & 555 & $46,0 \%$ & $27,6 \%$ & $14,4 \%$ \\
\hline Mato Grosso & 442.803 & 722.348 & 412.780 & 589.971 & 1.073 & 1.224 & $63,1 \%$ & $42,9 \%$ & $14,1 \%$ \\
\hline Rondônia & 475.596 & 716.829 & 497.771 & 857.660 & 955 & 836 & $50,7 \%$ & $72,3 \%$ & $-12,5 \%$ \\
\hline Pernambuco & 360.266 & 609.056 & 359.240 & 431.429 & 1.003 & 1.412 & $69,1 \%$ & $20,1 \%$ & $40,8 \%$ \\
\hline
\end{tabular}

Fonte: Pesquisa Pecuária Municipal - IBGE, dados da pesquisa

Já em relação ao número de vacas, o Rio Grande do Sul possuía o quinto maior rebanho do país (1,51 milhão de cabeças) bem inferior ao número de vacas em lactação de Goiás (2,69 milhão de cabeças).

Como dito anteriormente, o aumento da produção de leite se deve a dois fatores: aumento do número de vacas ordenhadas (em lactação) e da produtividade (litros de leite por vaca ao ano). Com base na Tabela 1 verifica-se que as estratégias dos estados Rio Grande do Sul e Goiás foram diferenciadas uma vez que no Rio Grande do Sul o aumento da produtividade $(44,7 \%)$ foi maior do que o aumento do número de vacas $(25,9 \%)$ enquanto no estado de Goiás ocorreu o oposto (o aumento do número de vacas em lactação $(26,9 \%)$ foi maior do que o aumento da produtividade $(20,3 \%))$. Observe que a menor produtividade de Goiás pode estar penalizando o produtor rural, afetando sua lucratividade e, até mesmo, pressionando os custos da matéria prima para a indústria, afetando sua competitividade.

Interessante verificar que todos os estados avançaram a produção à exceção do estado de São Paulo (maior estado consumidor) que reduziu a produção em $5,2 \%$, devido à redução do número de vacas leiteiras. Outro estado que chama atenção é Rondônia que aumentou a produção de leite com redução da produtividade.

Na média, o crescimento da produção de leite no Brasil no período em análise $(57,5 \%)$ sendo o aumento de produtividade $(25,7 \%)$ maior do que o aumento do 
número de vacas (25,3\%), classificado por Gomes (1991) como intensivo. Os estados do Rio Grande do Sul, Paraná e Pernambuco tiveram um crescimento de produtividade $(44,7 \% ; 49,5 \%$ e 40,8\% respectivamente) maior do que o crescimento do número de vacas, tendo um crescimento intensivo. Já os estados de Minas Gerais, Goiás, Santa Catarina, Bahia, Mato Grosso, Rondônia tiveram comportamento oposto, com crescimento de produtividade $(17,4 \% ; 20,3 \% ; 40,2 \% ; 14,4 \% ; 14,1 \%$ e $-12,5 \%)$ menor do que o crescimento do número de vacas.

Interessante observar a Tabela 2 que mostra a produtividade marginal entre 2001 e 2012 (variação no número de litros de leite/variação do número de vacas ordenhadas) obtida pelos principais estados produtores de leite brasileiro. O estado de maior produtividade marginal foi o Rio Grande do Sul, com valor de 5.851 litros de leite por vaca ordenhada superior às médias observadas na Nova Zelândia (4.099 kg) e Argentina (5.326 kg). Observando esse indicador chama atenção a produtividade marginal dos estados da Bahia (maior do que a produtividade média observada em 2001, mas bastante baixa) e de Rondônia (menor do que a produtividade média do início do período que já era bastante reduzida).

Comparando as Tabelas 1 e 2, observa-se que a produtividade marginal das vacas descartadas no estado de São Paulo eram de reduzida produtividade (396 litros por vaca), mas que no entanto não houve uma mudança estrutural no sistema produtivo de forma a influenciar a mudança do nível de produtividade entre o início e fim do período analisado.

Pode-se aqui fazer uma reflexão sobre o comportamento dessa função de produção macro aqui investigada. Embora a produtividade marginal do estado de São Paulo possa não refletir a real produtividade das vacas descartadas, ela reflete a eficiência territorial e a lucratividade que essa produção possa alcançar. O esforço coletivo pode ser classificado como de baixa eficiência econômica, comparado com às médias e incrementos de outros estados da federação. 
Tabela 2 - Produtividades marginais do Brasil e principais estados produtores de leite (litros de leite/vaca) - 2001/2012

\begin{tabular}{l|c|c|c|c}
\hline \multicolumn{1}{c|}{$\begin{array}{c}\text { Brasil e Unidades } \\
\text { da Federação }\end{array}$} & $\begin{array}{c}\text { Variação da } \\
\text { produção }\end{array}$ & $\begin{array}{c}\text { Variação de } \\
\text { vacas }\end{array}$ & $\begin{array}{c}\text { Produtividade } \\
\text { marginal }\end{array}$ & $\begin{array}{c}\text { Produtividade } \\
\text { média 2001 }\end{array}$ \\
\hline Rio Grande do Sul & 1.827 .433 & 312.318 & 5.851 & 1.845 \\
Paraná & 2.078 .879 & 465.299 & 4.468 & 1.642 \\
Pernambuco & 248.790 & 72.189 & 3.446 & 1.003 \\
Santa Catarina & 1.641 .567 & 479.481 & 3.424 & 1.798 \\
\hline Brasil & 11.794 .468 & 4.609 .568 & 2.559 & 1.127 \\
Minas Gerais & 2.924 .761 & 1.199 .655 & 2.438 & 1.337 \\
Goiás & 1.224 .589 & 571.570 & 2.143 & 1.095 \\
Mato Grosso & 279.545 & 177.191 & 1.578 & 1.073 \\
Bahia & 339.998 & 420.773 & 808 & 486 \\
Rondônia & 241.233 & 359.889 & 670 & 955 \\
São Paulo & -93.302 & -262.300 & 356 & 1.029 \\
\hline
\end{tabular}

Fonte: Tabela 1

Observa-se, na Figura 1, que no Rio Grande do Sul houve um aumento da produção de leite de 1,45 bilhões de litros de leite em 1990 para 4,04 bilhões de litros de leite em 2012, registrando uma elevação de $179 \%$ no período e um crescimento anual na produção de leite de 4,7\% ao ano. Entre 2001 e 2012 a taxa de crescimento anual foi de 5,6\% ao ano. Essa taxa de crescimento fica ainda mais expressiva quando se observa que o Rio Grande do sul é o segundo maior produtor de leite do Brasil atrás somente de Minas Gerais, razão por que a base de cálculo é alta. No entanto, os estados de Santa Catarina e Paraná tiveram um crescimento na produção entre 2001 a 2012 mais elevados, de 8,8\% e 7,0\% ao ano respectivamente. $\mathrm{O}$ crescimento médio do Brasil foi de 4,2\% ao ano enquanto o de Minas Gerais foi de $3,7 \%$.

A Figura 2 mostra as taxa de crescimento anual da produção de leite do Rio Grande do Sul ano a ano. A linha sobre as barras mostra uma média móvel de dois anos a qual revela um padrão cíclico de crescimento. Além da aceleração do crescimento da quantidade produzida, verificou-se que entre os anos de 2007 e 2008 a produção de leite gaúcha cresceu a um ritmo superior a $12 \%$ ao ano, o que permitiu alavancar a produção do estado superando a produção de Goiás e Paraná. 
Figura 1 - Evolução da produção de leite no Rio Grande do Sul - em bilhões de litros

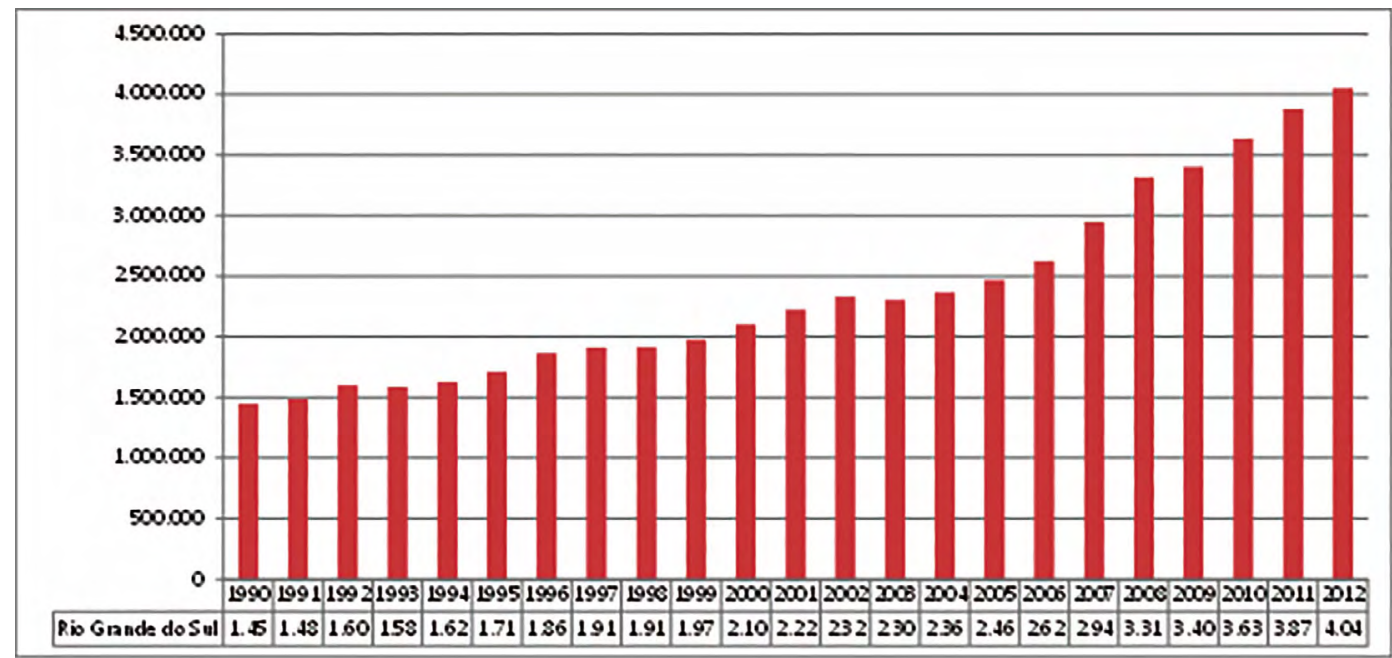

Fonte: Pesquisa Pecuária Municipal - IBGE

Figura 2 - Taxa de crescimento anual da produção de leite gaúcha

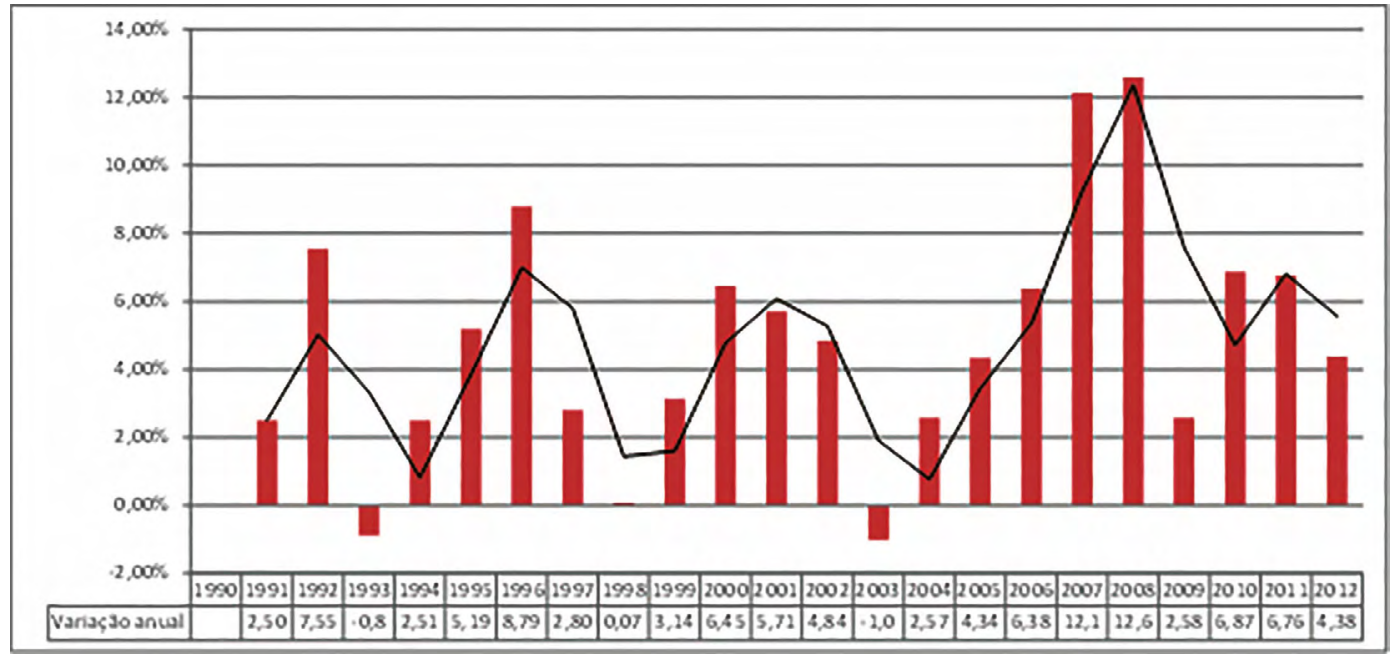

Fonte: Pesquisa Pecuária Municipal - IBGE 


\section{Fontes de crescimento da produção de leite no estado do RS e regiões coredianas}

O estado do Rio Grande do Sul é subdivido em 28 regiões de planejamento, para efeitos de distribuição do orçamento público. Em cada região de planejamento há um Corede com o objetivo de reunir lideranças públicas e privadas de todos os municípios componentes para estabelecer planos e objetivos de desenvolvimento comuns. Esse é o recorte geográfico utilizado na presente análise.

Tabela 3 - Fontes de crescimento da produção de leite - Rio Grande do Sul e regiões coredianas

\begin{tabular}{|c|c|c|c|c|c|c|c|c|c|}
\hline \multirow[b]{2}{*}{ Coredes } & \multicolumn{2}{|c|}{$\begin{array}{l}\text { Produção } \\
\text { (1.000 litros) }\end{array}$} & \multicolumn{2}{|c|}{$\begin{array}{l}\text { Vacas Ordenhadas } \\
\text { (cabeças) }\end{array}$} & \multicolumn{2}{|c|}{ Produtividade } & \multirow{2}{*}{ 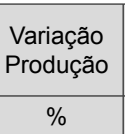 } & \multirow{2}{*}{$\begin{array}{c}\begin{array}{c}\text { Variação } \\
\text { Vacas }\end{array} \\
\%\end{array}$} & \multirow{2}{*}{$\begin{array}{c}\text { Variação } \\
\text { Produti- } \\
\text { vidade }\end{array}$} \\
\hline & 2001 & 2012 & 2001 & 2012 & 2001 & 2012 & & & \\
\hline Produção & 155.318 & 414.151 & 59.282 & 91.356 & 2.620 & 4.533 & $166,65 \%$ & $54,1 \%$ & $73,0 \%$ \\
\hline Fronteira Noroeste & 222.153 & 378.118 & 113.445 & 111.760 & 1.958 & 3.383 & $70,21 \%$ & $-1,5 \%$ & $72,8 \%$ \\
\hline Vale do Taquari & 165.005 & 358.830 & 72.687 & 106.699 & 2.270 & 3.363 & $117,47 \%$ & $46,8 \%$ & $48,1 \%$ \\
\hline Celeiro & 143.998 & 298.896 & 64.699 & 90.122 & 2.226 & 3.317 & $107,57 \%$ & $39,3 \%$ & $49,0 \%$ \\
\hline Serra & 152.218 & 271.143 & 84.889 & 82.042 & 1.793 & 3.305 & $78,13 \%$ & $-3,4 \%$ & $84,3 \%$ \\
\hline Norte & 111.091 & 246.035 & 59.785 & 99.651 & 1.858 & 2.469 & $121,47 \%$ & $66,7 \%$ & $32,9 \%$ \\
\hline Noroeste Colonial & 126.401 & 243.184 & 48.500 & 67.140 & 2.606 & 3.622 & $92,39 \%$ & $38,4 \%$ & $39,0 \%$ \\
\hline Nordeste & 78.882 & 240.790 & 40.305 & 73.612 & 1.957 & 3.271 & $205,25 \%$ & $82,6 \%$ & $67,1 \%$ \\
\hline Rio da Várzea & 82.990 & 224.439 & 42.040 & 91.102 & 1.974 & 2.464 & $170,44 \%$ & $116,7 \%$ & $24,8 \%$ \\
\hline Missões & 134.612 & 191.624 & 77.233 & 99.008 & 1.743 & 1.935 & $42,35 \%$ & $28,2 \%$ & $11,0 \%$ \\
\hline Alto Jacuí & 129.094 & 181.787 & 41.241 & 48.980 & 3.130 & 3.711 & $40,82 \%$ & $18,8 \%$ & $18,6 \%$ \\
\hline Médio Alto Uruguai & 63.247 & 159.297 & 44.381 & 92.336 & 1.425 & 1.725 & $151,86 \%$ & $108,1 \%$ & $21,1 \%$ \\
\hline Sul & 126.344 & 143.162 & 76.666 & 62.968 & 1.648 & 2.274 & $13,31 \%$ & $-17,9 \%$ & $38,0 \%$ \\
\hline Alto da Serra do Botucaraí & 61.627 & 133.876 & 29.146 & 41.344 & 2.114 & 3.238 & $117,24 \%$ & $41,9 \%$ & $53,1 \%$ \\
\hline Fronteira Oeste & 52.036 & 84.452 & 41.959 & 48.337 & 1.240 & 1.747 & $62,30 \%$ & $15,2 \%$ & $40,9 \%$ \\
\hline Vale do Caí & 39.075 & 71.694 & 18.686 & 34.788 & 2.091 & 2.061 & $83,48 \%$ & $86,2 \%$ & $-1,4 \%$ \\
\hline Metropolitano Delta do Jacuí & 37.163 & 61.915 & 18.962 & 23.250 & 1.960 & 2.663 & $66,60 \%$ & $22,6 \%$ & $35,9 \%$ \\
\hline Campanha & 49.703 & 60.928 & 23.221 & 27.728 & 2.140 & 2.197 & $22,58 \%$ & $19,4 \%$ & $2,7 \%$ \\
\hline Vale do Rio Pardo & 55.480 & 59.530 & 45.325 & 46.907 & 1.224 & 1.269 & $7,30 \%$ & $3,5 \%$ & $3,7 \%$ \\
\hline Central & 63.136 & 53.948 & 48.599 & 41.698 & 1.299 & 1.294 & $-14,55 \%$ & $-14,2 \%$ & $-0,4 \%$ \\
\hline Campos de Cima da Serra & 23.593 & 40.503 & 36.449 & 28.395 & 647 & 1.426 & $71,67 \%$ & $-22,1 \%$ & $120,4 \%$ \\
\hline Hortênsias & 35.975 & 28.593 & 35.667 & 30.648 & 1.009 & 933 & $-20,52 \%$ & $-14,1 \%$ & $-7,5 \%$ \\
\hline Vale do Jaguari & 21.533 & 28.317 & 22.170 & 25.405 & 971 & 1.115 & $31,51 \%$ & $14,6 \%$ & $14,8 \%$ \\
\hline Paranhana-Encosta da Serra & 24.466 & 21.200 & 11.517 & 10.369 & 2.124 & 2.045 & $-13,35 \%$ & $-10,0 \%$ & $-3,8 \%$ \\
\hline Jacuí-Centro & 19.266 & 17.093 & 17.348 & 17.239 & 1.111 & 992 & $-11,28 \%$ & $-0,6 \%$ & $-10,7 \%$ \\
\hline Vale do Rio dos Sinos & 18.363 & 15.547 & 7.789 & 7.915 & 2.358 & 1.964 & $-15,34 \%$ & $1,6 \%$ & $-16,7 \%$ \\
\hline Centro-Sul & 17.061 & 12.345 & 12.495 & 9.150 & 1.365 & 1.349 & $-27,64 \%$ & $-26,8 \%$ & $-1,2 \%$ \\
\hline Litoral & 12.233 & 8.098 & 9.885 & 6.740 & 1.238 & 1.201 & $-33,80 \%$ & $-31,8 \%$ & $-2,9 \%$ \\
\hline Rio Grande do Sul & 2.222 .063 & 4.049 .495 & 1.204 .371 & 1.516 .689 & 1.845 & 2.670 & $82,2 \%$ & $25,9 \%$ & $44,7 \%$ \\
\hline
\end{tabular}

Fonte: Pesquisa Pecuária Municipal - IBGE, dados da pesquisa. 
A Tabela 3 mostra os valores e as variações observadas de produção de leite, número de vacas e produtividade para os anos 2001 e 2012 para o estado do Rio Grande do Sul e regiões coredianas. Os coredes estão ordenados pela produtividade de 2012.

Observa-se que, no Rio Grande do Sul, a Região do Corede Produção é a de maior produção de leite (414 mil litros de leite) e a de maior produtividade média (4.533 litros/vaca/ano). A produtividade da Região da Produção é 70\% maior que a média do estado do Rio Grande do Sul (2.670 litros/vaca/ano) e 220\% maior do que a média brasileira (1.417 litro/vaca/ano).

Analisando as 10 regiões de maior produtividade em 2012, verifica-se que essas apresentam trajetórias de crescimento diferenciadas a exemplo dos estados brasileiros. Os Coredes Produção, Vale do Taquari, Celeiro e Noroeste Colonial tiveram o crescimento da produtividade maior do que o aumento do número de vacas, classificado por Gomes (1991) como crescimento intensivo. Já os Coredes Norte, Nordeste, Rio da Várzea e Missões aumentaram a produção com um maior incremento originado do aumento do número de vacas, classificado por Gomes (1991) como crescimento extensivo. Já os Coredes Fronteira Noroeste, Serra, Sul e Campos de Cima da Serra aumentaram a produção de leite com aumento da produtividade e redução do número de vacas. Interessante verificar o aumento de $120 \%$ da produtividade das vacas do Corede Campos de Cima da Serra, ou até mesmo a alta produtividade média das regiões Fronteira Noroeste e Serra, que em termos líquidos reduziram o tamanho do rebanho, justificado pelo descarte de vacas poucos produtivas e/ou pela aquisição de vacas com melhor genética pelos produtores mais especializados.

Sete regiões reduziram a produção, todas elas com redução de produtividade média. São elas: Central, Hortênsias, Paranhana-Encosta da Serra, Jacuí-Centro, Vale do Rio dos Sinos, Centro-Sul e Litoral.

A Tabela 4 mostra a produtividade marginal das regiões gaúchas entre os anos de 2001 e 2012. Observa-se que a produtividade marginal da região da Produção foi de 8.070 litros \vaca, seguido pelas regiões do Alto do Jacuí (6.809 litros \vaca), Noroeste Colonial (6.265 litros \vaca) e Celeiro (6.093 litros \vaca).

Cabe salientar que a produtividade incremental obtida entre os anos $2001 \mathrm{e}$ 2012 por essas regiões é muito relevante em termos internacionais, já que foi superior à produtividade média observada, em 2012, na Nova Zelândia (4.099 kg), na Argentina $(5.326 \mathrm{~kg})$ e na União Europeia de $(6.030 \mathrm{~kg})$ e, somente inferior a dos Estados Unidos $(9.837 \mathrm{~kg})$. 
A Tabela 4 permite observar o comportamento agregado das sete regiões que reduziram a produção. Duas delas, Jacuí Centro e Vale do Rio dos Sinos reduziram a produção com o rebanho praticamente estabilizado comparando $2001 \mathrm{e}$ 2012, o que implica dizer que a produtividade média é diminuída. Por outro viés, as demais cinco regiões reduziram a produção de leite agregada à redução do tamanho do rebanho. A coluna de produtividade marginal mostra a produtividade marginal agregada das vacas descartadas, que são maiores do que a produtividade média do início do período (2001). Implica dizer que foram descartadas vacas com produtividade agregada maior do que a do início do período e, consequentemente, reduziram a produtividade agregada média de 2012 . O que poderia explicar esse comportamento? Obviamente, se observa a quantidade total de vacas nessas regiões e não o número médio de vacas por propriedade agrícola. O que implica inferir que embora a produtividade média das vacas descartadas sejam maiores do que a média regional até mesmo de fim do período analisado (2012), as unidades produtivas poderiam estar operando abaixo do ponto de equilíbrio na atividade leiteira e obtinham uma lucratividade menor do que culturas e atividades alternativas. Assim do ponto de vista econômico e individual a atividade leiteira dessas unidades produtivas deixaram de ser atraentes. Esse fato mostra a necessidade de uma pesquisa junto às unidades produtivas de modo a se elaborar um diagnóstico mais preciso e um plano de ação regional diferenciado. 
Tabela 4 - Produtividade marginal do Rio Grande do Sul e regiões coredianas (litros de leite/vaca) $-2001 / 2012$

\begin{tabular}{|c|c|c|c|c|}
\hline $\mathrm{RS}$ e regiões coredianas & \begin{tabular}{|c|}
$\begin{array}{c}\text { Variação da produção } \\
\text { (1.000 litros) }\end{array}$ \\
\end{tabular} & $\begin{array}{c}\text { Variação de vacas } \\
\text { (cabeças) }\end{array}$ & $\begin{array}{c}\text { Produtividade } \\
\text { marginal }\end{array}$ & $\begin{array}{c}\text { Produtividade } \\
\text { média } 2001\end{array}$ \\
\hline Rio Grande do Sul & 1.827 .432 & 312.318 & 5.851 & 1.845 \\
\hline Produção & 258.833 & 32.074 & 8.070 & 2.620 \\
\hline Vale do Taquari & 193.825 & 34.012 & 5.699 & 2.270 \\
\hline Nordeste & 161.908 & 33.307 & 4.861 & 1.957 \\
\hline Fronteira Noroeste & 155.965 & -1.685 & * & 1.958 \\
\hline Celeiro & 154.898 & 25.423 & 6.093 & 2.226 \\
\hline Rio da Várzea & 141.449 & 49.062 & 2.883 & 1.974 \\
\hline Norte & 134.944 & 39.866 & 3.385 & 1.858 \\
\hline Serra & 118.925 & -2.847 & * & 1.793 \\
\hline Noroeste Colonial & 116.783 & 18.640 & 6.265 & 2.606 \\
\hline Médio Alto Uruguai & 96.050 & 47.955 & 2.003 & 1.425 \\
\hline Alto da Serra do Botucaraí & 72.249 & 12.198 & 5.923 & 2.114 \\
\hline Missões & 57.012 & 21.775 & 2.618 & 1.743 \\
\hline Alto Jacuí & 52.693 & 7.739 & 6.809 & 3.130 \\
\hline Vale do Caí & 32.619 & 16.102 & 2.026 & 2.091 \\
\hline Fronteira Oeste & 32.416 & 6.378 & 5.082 & 1.240 \\
\hline Metropolitano Delta do Jacuí & 24.752 & 4.288 & 5.772 & 1.960 \\
\hline Campos de Cima da Serra & 16.910 & -8.054 & * & 647 \\
\hline Sul & 16.818 & -13.698 & * & 1.648 \\
\hline Campanha & 11.225 & 4.507 & 2.491 & 2.140 \\
\hline Vale do Jaguari & 6.784 & 3.235 & 2.097 & 971 \\
\hline Vale Do Rio Pardo & 4.050 & 1.582 & 2.560 & 1.224 \\
\hline Jacuí-Centro & -2.173 & -109 & ** & 1.111 \\
\hline Vale do Rio dos Sinos & -2.816 & 126 & ** & 2.358 \\
\hline Paranhana-Encosta da Serra & -3.266 & -1.148 & 2.845 & 2.124 \\
\hline Litoral & -4.135 & -3.145 & 1.315 & 1.238 \\
\hline Centro-Sul & -4.716 & -3.345 & 1.410 & 1.365 \\
\hline Hortênsias & -7.382 & -5.019 & 1.471 & 1.009 \\
\hline Central & -9.188 & -6.901 & 1.331 & 1.299 \\
\hline
\end{tabular}

Fonte: Pesquisa Pecuária Municipal - IBGE, dados da pesquisa.

A Figura 3 mostra os Coredes com maior concentração de produção no estado, em 2012. São apresentados três segmentos de produção: até 100 milhões de litros de leite ao ano (até $2,47 \%$ de participação na produção estadual), de 100 a 200 milhões (de $2,47 \%$ a $4,94 \%$ da produção estadual) e de 200 a 414 milhões de litros de leite (acima de 4,94\% da produção estadual). Verifica-se que a produção de leite está concentrada na porção norte do estado. 
A área mais escura refere-se aos nove Coredes de maior produção, acima de 200 milhões de litros de leite por ano, e concentram 66\% do total produzido no estado. O Corede com maior produção de leite é o da região da Produção que respondeu por $10,23 \%$ da produção total de leite dos gaúchos em 2012, seguido do corede Fronteira Noroeste Colonial $(9,34 \%)$, Vale do Taquari $(8,86 \%)$, Celeiro $(7,38 \%)$ e Serra $(6,70 \%)$.

A área de cor mais clara refere-se aos cinco Coredes de produção intermediária, entre 100 e 200 milhões de litros de leite e concentram $20 \%$ da produção estadual. As áreas em branco referem-se às regiões de menor produção.

Figura 3 - Concentração espacial da produção de leite no RS em 2012

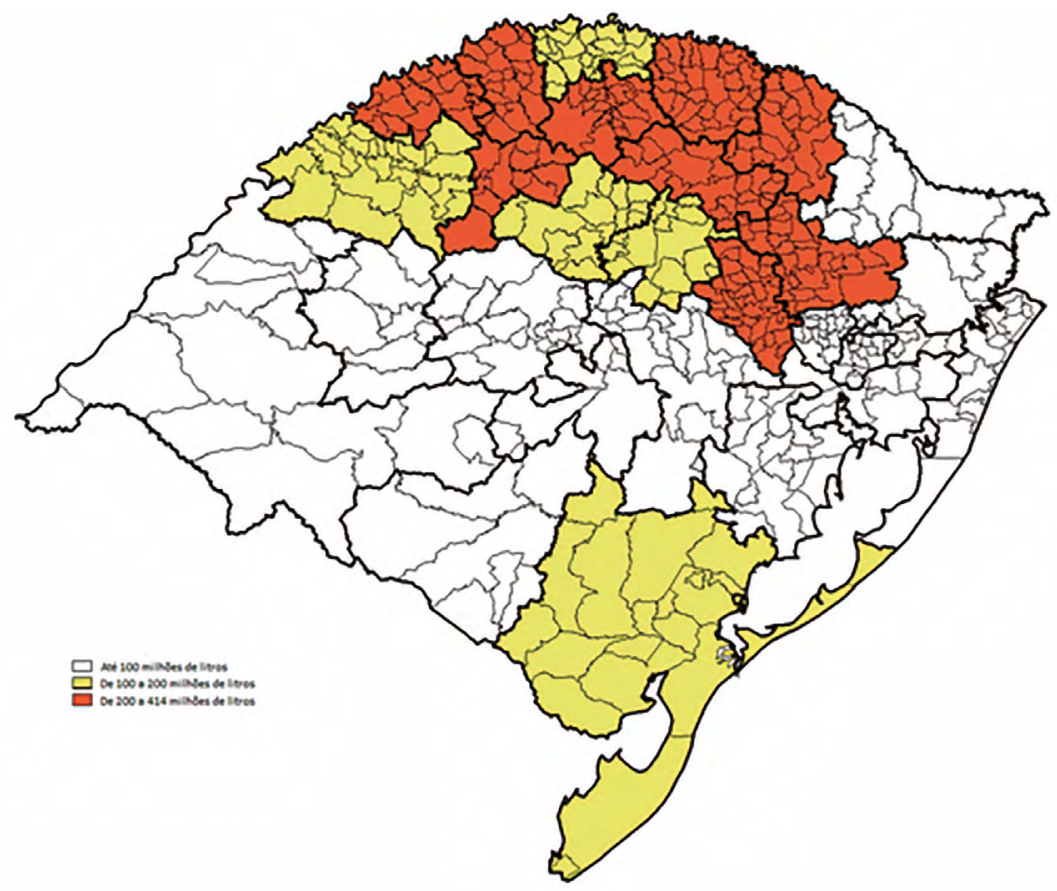

Fonte: Pesquisa Pecuária Municipal - IBGE, elaborada pelos autores.

A Figura 4 apresenta um gráfico de três dimensões elaborado com os dados da Tabela 3. O eixo horizontal é o de participação das regiões na produção estadual e o eixo vertical, o crescimento percentual da produção regional observado entre os anos 2001 e 2012. Observa-se que há uma correlação positiva entre escala de produção regional e velocidade de crescimento, ou seja, as regiões coredianas com maior escala de produção são as que mais crescem. 
O tamanho das bolhas possibilita a análise de uma terceira dimensão que é o volume de produção de leite, em litros, acrescido no período (produção marginal). Assim, observando a Figura 4, pode-se afirmar também que as regiões gaúchas que tiveram maior crescimento da produção são também as que geraram maiores excedentes de produção exportáveis.

A Figura 4 claramente permite a diferenciação visual das regiões de maior escala e mais dinâmicas daquelas de menor crescimento e menor tamanho. As bacias leiteiras das regiões mais dinâmicas possuem elevada produtividade comparada às médias dos estados brasileiros e países e beneficiam toda a população ali residente uma vez que trazem renda de fora da região para dentro da região, gerando encadeamentos produtivos em outros setores da economia, além das atividades ligadas à atividade láctea em si. A mudança estrutural observada se deve à exploração das vantagens comparativas e de adoção de tecnologias que permitem maior produtividade e lucratividade. Em outras palavras, no longo prazo, o deslocamento da escala da fazenda para uma tecnologia superior leva a firma a ter rendimentos crescentes de escala, chamados de externos à firma. $\mathrm{O}$ crescimento perpétuo é feito possível na presença de retornos crescentes à escala ou externalidades.

Figura 4 - Participação regional versus taxa de crescimento e geração de excedentes

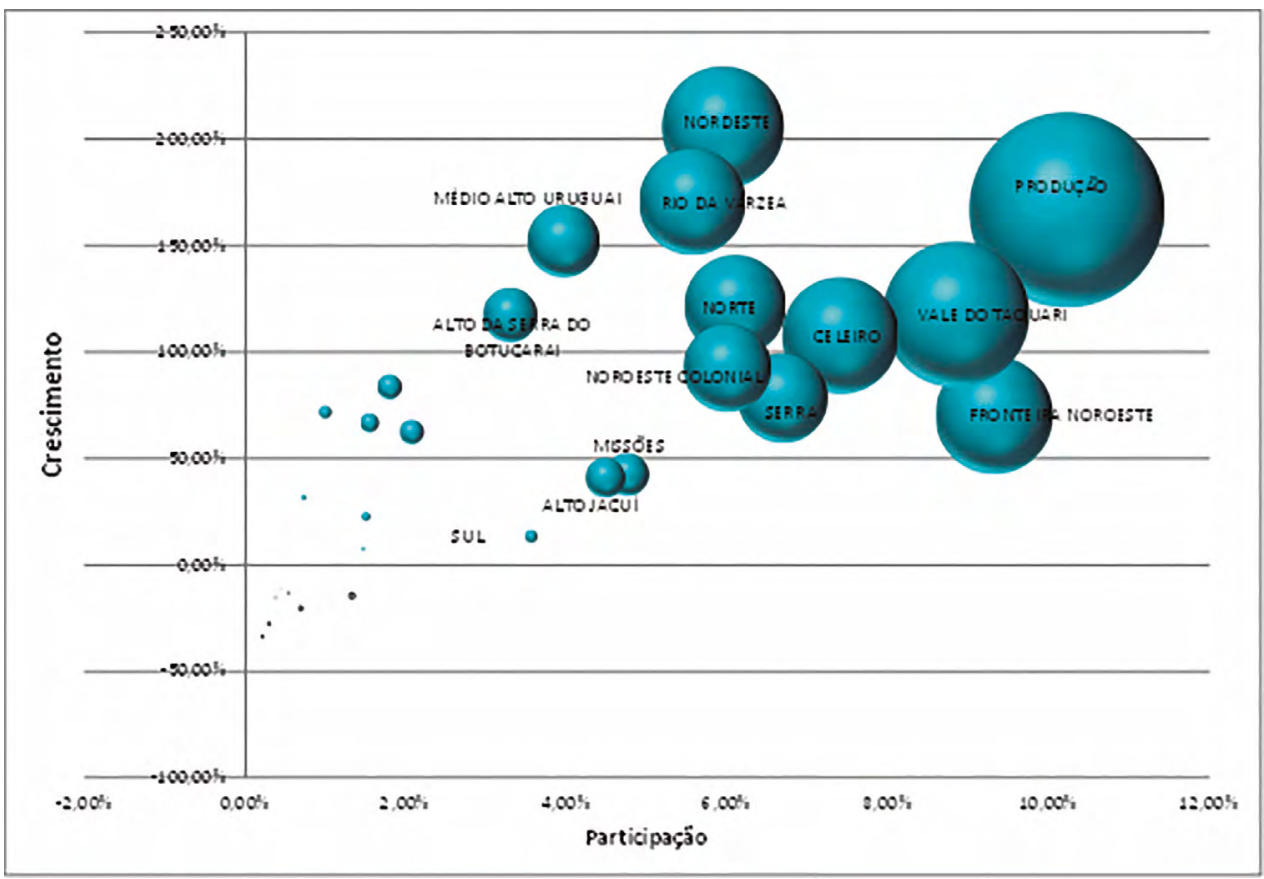

Fonte: Pesquisa Pecuária Municipal - IBGE, elaborada pelos autores. 


\section{Fontes de crescimento da produção de leite no Corede Produção e seus municípios}

A Tabela 5 mostra a decomposição do crescimento da produção de leite para o Corede Produção e seus munícipios. Os municípios foram ordenados pela produtividade de 2012. Na Região do Corede Produção - região de maior produção e produtividade do estado do RS - o aumento de $166,6 \%$ da produção de leite, entre 2001 e 2012, é explicado pelo aumento de $73 \%$ do aumento da produtividade das vacas e pelo aumento de $54,1 \%$ do número de vacas em lactação, sendo este tipo de crescimento classificado por Gomes (1991) como intensivo.

Todos os municípios da região do Corede Produção tiveram aumento de produção de leite entre 2001 e 2012, e podem ser divididos em quatro grupos, classificados pelas diferenças das fontes de crescimento da produção.

O primeiro grupo é formado apenas pelo município de Passo Fundo que teve diminuição do número de vacas (queda de $6,1 \%$ ) e aumento de produtividade. Todos os demais municípios da região tiveram aumento do número de vacas no período.

O segundo grupo é formado pelos municípios que tiveram um aumento de produtividade maior do que o aumento do número de vacas, ou seja, aumentaram a produção com custos unitários de produção decrescentes, classificado por Gomes (1991) como crescimento intensivo. São eles: Pontão, Vanini, Santo Antônio do Palma, Coxilha, Marau, Vila Maria, Camargo, Mato Castelhano, Ciríaco e Ernestina.

O terceiro grupo é formado pelos municípios que tiveram um aumento do número de vacas maior do que o aumento de produtividade, classificado por Gomes (1991) como extensivo. Ou seja, aumentaram a produção com ganhos de produtividade e redução de custos unitários de produção. São eles: Casca, São Domingos do Sul, David Canabarro, Nova Alvorada, Muliterno, Gentil, Carazinho e Santo Antônio do Planalto.

O quarto grupo é formado pelos municípios que apresentaram aumento do número de vacas com diminuição na produtividade dessas - Almirante Tamandaré do Sul e Coqueiros do Sul. Esses municípios também tiveram o menor crescimento de produção de leite da região. Os custos unitários de produção crescentes podem desestimular os produtores para o aumento da escala da propriedade. 
Tabela 5 - Fontes de crescimento da produção de leite - Corede Produção e municípios

\begin{tabular}{|c|c|c|c|c|c|c|c|c|c|}
\hline \multirow[b]{2}{*}{ Região e Municípios } & \multicolumn{2}{|c|}{$\begin{array}{c}\text { Produção } \\
\text { (1.000 litros) }\end{array}$} & \multicolumn{2}{|c|}{$\begin{array}{c}\text { Vacas } \\
\text { (cabeças) }\end{array}$} & \multicolumn{2}{|c|}{ Produtividade } & \multirow{2}{*}{$\begin{array}{c}\begin{array}{c}\text { Variação } \\
\text { Produção }\end{array} \\
\%\end{array}$} & \multirow{2}{*}{$\begin{array}{c}\begin{array}{c}\text { Variação } \\
\text { Vacas }\end{array} \\
\%\end{array}$} & \multirow{2}{*}{$\begin{array}{c}\begin{array}{c}\text { Variação } \\
\text { Produtividade }\end{array} \\
\%\end{array}$} \\
\hline & 2001 & 2012 & 2001 & 2012 & 2001 & 2012 & & & \\
\hline Casca & 15.114 & 65.200 & 5.038 & 12.074 & 3.000 & 5.400 & $331,39 \%$ & $139,7 \%$ & $80,0 \%$ \\
\hline Pontão & 7.834 & 29.045 & 3.264 & 5.695 & 2.400 & 5.100 & $270,76 \%$ & $74,5 \%$ & $112,5 \%$ \\
\hline Vanini & 2.835 & 8.356 & 1.053 & 1.688 & 2.692 & 4.950 & $194,74 \%$ & $60,3 \%$ & $83,9 \%$ \\
\hline São Domingos do Sul & 3.051 & 12.113 & 1.017 & 2.447 & 3.000 & 4.950 & $297,02 \%$ & $140,6 \%$ & $65,0 \%$ \\
\hline Santo Antônio do Palma & 3.336 & 10.553 & 1.390 & 2.132 & 2.400 & 4.950 & $216,34 \%$ & $53,4 \%$ & $106,2 \%$ \\
\hline Coxilha & 5.722 & 15.514 & 2.384 & 3.232 & 2.400 & 4.800 & $171,13 \%$ & $35,6 \%$ & $100,0 \%$ \\
\hline Passo Fundo & 22.023 & 33.077 & 7.341 & 6.891 & 3.000 & 4.800 & $50,19 \%$ & $-6,1 \%$ & $60,0 \%$ \\
\hline Marau & 20.750 & 52.733 & 8.646 & 10.986 & 2.400 & 4.800 & $154,13 \%$ & $27,1 \%$ & $100,0 \%$ \\
\hline Vila Maria & 10.962 & 30.960 & 4.060 & 6.450 & 2.700 & 4.800 & $182,43 \%$ & $58,9 \%$ & $77,8 \%$ \\
\hline David Canabarro & 8.352 & 27.062 & 2.784 & 5.638 & 3.000 & 4.800 & $224,02 \%$ & $102,5 \%$ & $60,0 \%$ \\
\hline Camargo & 6.276 & 15.566 & 2.615 & 3.243 & 2.400 & 4.800 & $148,02 \%$ & $24,0 \%$ & $100,0 \%$ \\
\hline Nova Alvorada & 4.000 & 11.096 & 1.300 & 2.390 & 3.077 & 4.643 & $177,40 \%$ & $83,8 \%$ & $50,9 \%$ \\
\hline Mato Castelhano & 5.146 & 11.903 & 1.906 & 2.645 & 2.700 & 4.500 & $131,31 \%$ & $38,8 \%$ & $66,7 \%$ \\
\hline Ciríaco & 8.600 & 25.347 & 4.095 & 6.035 & 2.100 & 4.200 & $194,73 \%$ & $47,4 \%$ & $100,0 \%$ \\
\hline Ernestina & 7.159 & 15.334 & 2.512 & 3.651 & 2.850 & 4.200 & $114,19 \%$ & $45,3 \%$ & $47,4 \%$ \\
\hline Muliterno & 1.537 & 10.483 & 732 & 2496 & 2.100 & 4.200 & $582,04 \%$ & $241,0 \%$ & $100,0 \%$ \\
\hline Gentil & 3.056 & 12.219 & 1.455 & 3.133 & 2.100 & 3.900 & $299,84 \%$ & $115,3 \%$ & $85,7 \%$ \\
\hline Carazinho & 5.369 & 8.543 & 2.110 & 2.700 & 2.545 & 3.164 & $59,12 \%$ & $28,0 \%$ & $24,3 \%$ \\
\hline Santo Antônio do Planalto & 3.085 & 5.548 & 1.150 & 1.940 & 2.683 & 2.860 & $79,84 \%$ & $68,7 \%$ & $6,6 \%$ \\
\hline Almirante Tamandaré do Sul & 6.576 & 7.624 & 2.480 & 3.240 & 2.652 & 2.353 & $15,94 \%$ & $30,6 \%$ & $-11,3 \%$ \\
\hline Coqueiros do Sul & 4.535 & 5.875 & 1.950 & 2.650 & 2.326 & 2.217 & $29,55 \%$ & $35,9 \%$ & $-4,7 \%$ \\
\hline Corede Produção & 155.318 & 414.151 & 59.282 & 91.356 & 2.620 & 4.533 & $166,6 \%$ & $54,1 \%$ & $73,0 \%$ \\
\hline
\end{tabular}

Fonte: Pesquisa Pecuária Municipal - IBGE, dados da pesquisa

Dentre os 21 municípios da região, destaca-se o município de Casca que possui a maior produtividade regional, de 5.400 litros/vaca/ano; $19,3 \%$ maior do que a média regional (4.533 litros/vaca/ano); 102,2\% maior do que a média estadual (2.670 litros/vaca/ano); e 281,1\% maior do que a média nacional (1.417 litros/vaca/ano). Em termos regionais o município de Casca foi o que apresentou o segundo maior crescimento da produção de leite no período analisado (331,39\%) sendo superado apenas pelo município de Muliterno (592,04\%). O aumento de 331,39\% da produção de leite em Casca é explicado pelo aumento de 139,39\% do número de vacas e pelo aumento de $80 \%$ da produtividade das vacas.

A produção total de leite do município de Casca que é a maior do estado do Rio Grande do Sul com 65 mil litros em 2012, o que valeu o título de "capital gaúcha do leite". Já a produtividade (5.400 litros/vaca/ano) é a terceira maior do estado. A maior produtividade municipal do Rio Grande do Sul foi observada em Carlos Barbosa (5.768 litros/vaca/ano) na região do Corede Serra, seguido pelo município de Fortaleza dos Valos (5.760 litros/vaca/ano) da região do Corede Alto do Jacuí. 
A Figura 5 mostra um gráfico de três dimensões para os municípios do Corede Produção. $\mathrm{O}$ eixo horizontal mostra o peso da produção do município na produção regional, tendo 2012 como referência. $\mathrm{O}$ eixo vertical apresenta a taxa de crescimento observada na produção de leite entre os anos 2001 e 2012. O tamanho das bolhas mostra o volume de produção de leite, em litros, acrescido no período analisado (produção marginal).

Figura 5 - Participação regional versus taxa de crescimento e geração de excedentes

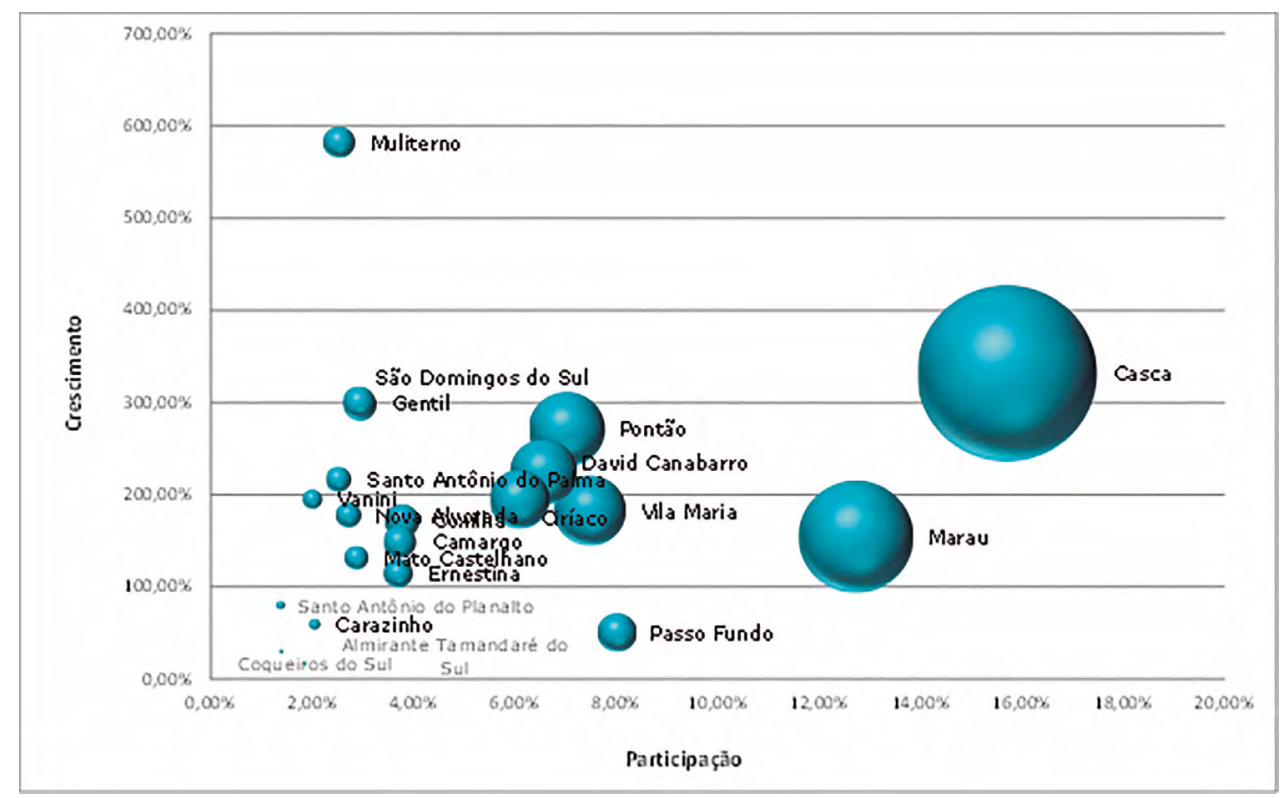

Fonte: Pesquisa Pecuária Municipal - IBGE, dados da pesquisa.

Observa-se que os municípios com maiores geração de excedentes de produção no período foram Casca (19,4\% da produção incremental regional) e Marau (12,4\% da produção incremental regional). Um grupo de municípios que se destaca pelo crescimento com excedentes gerados entre 6,5 e 8,2\% do excedente regional foi: Pontão, David Canabarro, Vila Maria e Ciríaco. Estes seis municípios produziram juntos 61,3\% do leite incremental produzido entre 2001 e 2012.

Por fim a Tabela 6 mostra a produtividade marginal agregada dos municípios da região da Produção, onde o município de maior produtividade marginal foi o de Camargo (14.793 litros/vaca), seguido de Marau (13.668 litros/vaca) e Coxilha 
(11.547 litros/vaca). Estas produtividades marginais superam a produtividade média dos Estados Unidos de $9.670 \mathrm{~kg}$.

Reforça-se novamente que se esta analisando uma função de produção agregada e não funções de produções micro, de firmas individuais, o que fica mais claro quando se observa os pequenos incrementos, em termos absolutos, do número de vacas de cada município. O que não invalida a análise da decomposição da fonte de crescimento e dos níveis médios e marginais de produção sejam eles municipais ou regionais.

Tabela 6 - Produtividade marginal da região da Produção e seus municípios (litros de leite/vaca) 2001/2012

\begin{tabular}{l|c|c|c|c|c}
\hline \multicolumn{1}{|c|}{ Região e municípios } & $\begin{array}{c}\text { Variação da } \\
\text { produção } \\
\mathbf{( 1 . 0 0 0 ~ l i t r o s )}\end{array}$ & $\begin{array}{c}\text { Variação de } \\
\text { vacas } \\
\text { (cabeças) }\end{array}$ & $\begin{array}{c}\text { Produti- } \\
\text { vidade } \\
\text { marginal }\end{array}$ & $\begin{array}{c}\text { Produti- } \\
\text { vidade média } \\
\mathbf{2 0 0 1}\end{array}$ & $\begin{array}{c}\text { Produti- } \\
\text { vidade média } \\
\mathbf{2 0 1 2}\end{array}$ \\
\hline Camargo & 9.290 & 628 & 14.793 & 2.400 & 4.800 \\
Marau & 31.983 & 2.340 & 13.668 & 2.400 & 4.800 \\
Coxilha & 9.792 & 848 & 11.547 & 2.400 & 4.800 \\
Santo Antônio do Palma & 7.217 & 742 & 9.726 & 2.400 & 4.950 \\
Mato Castelhano & 6.757 & 739 & 9.143 & 2.700 & 4.500 \\
Pontão & 21.211 & 2.431 & 8.725 & 2.400 & 5.100 \\
Vanini & 5.521 & 635 & 8.694 & 2.692 & 4.950 \\
Ciríaco & 16.747 & 1.940 & 8.632 & 2.100 & 4.200 \\
Vila Maria & 19.998 & 2.390 & 8.367 & 2.700 & 4.800 \\
Corede Produção & $\mathbf{2 5 8 . 8 3 3}$ & $\mathbf{3 2 . 0 7 4}$ & $\mathbf{8 . 0 7 0}$ & $\mathbf{2 . 6 2 0}$ & $\mathbf{4 . 5 3 3}$ \\
Ernestina & 8.175 & 1.139 & 7.177 & 2.850 & 4.200 \\
Casca & 50.086 & 7.036 & 7.119 & 3.000 & 5.400 \\
David Canabarro & 18.710 & 2.854 & 6.556 & 3.000 & 4.800 \\
Nova Alvorada & 7.096 & 1.090 & 6.510 & 3.077 & 4.643 \\
São Domingos do Sul & 9.062 & 1.430 & 6.337 & 3.000 & 4.950 \\
Gentil & 9.163 & 1.678 & 5.461 & 2.100 & 3.900 \\
Carazinho & 3.174 & 590 & 5.380 & 2.545 & 3.164 \\
Muliterno & 8.946 & 1.764 & 5.071 & 2.100 & 4.200 \\
Santo Antônio do Planalto & 2.463 & 790 & 3.118 & 2.683 & 2.860 \\
Coqueiros do Sul & 1.340 & 700 & 1.914 & 2.326 & 2.217 \\
Almirante Tamandaré do Sul & 1.048 & 760 & 1.379 & 2.652 & 2.353 \\
Passo Fundo & 11.054 & -450 & $*$ & 3.000 & 4.800 \\
\hline Fon & & & &
\end{tabular}

Fonte: Pesquisa Pecuária Municipal - IBGE, dados da pesquisa. 


\section{Fontes de crescimento da produção de leite nos principais países exportadores}

Para efeito de comparação dos resultados nos diferentes recortes espaciais brasileiros analisados com os obtidos pelos sistemas de produção de outros países e de suas estratégias de ação, a Tabela 7 mostra as fontes de crescimento entre 2001 e 2012 para os principais países exportadores de leite mundo.

Os dados do Brasil foram extraídos do IBGE e o volume de produção é medido em litros. Os dos demais países foram fornecidos pelo Departamento de Agricultura dos Estados Unidos e estão em kg. Os dados da União Europeia ficam um pouco distorcidos, pois em 2001 ela era composta por 25 países e em 2012 por 28 países. Não foi possível fazer uma desagregação.

Observe que entre 2001 e 2012 o Brasil foi o país que mais aumentou a produção de leite $(57,51 \%)$ seguido pela Nova Zelândia (56,26\%). Enquanto o Brasil teve um crescimento de produtividade maior do que o crescimento do número de animais (crescimento extensivo), a Nova Zelândia teve caminho oposto com crescimento do número de vacas maior $(41,07 \%)$ do que o aumento de produtividade $(10,76 \%)$, crescimento classificado por Gomes (1991) com extensivo.

Os Estados Unidos teve um crescimento intensivo com o rebanho quase estabilizado no período (aumento de 1,43\%) enquanto a sua produtividade aumentou $19,40 \%$, resultando num aumento de produção de $21,11 \%$.

Tabela 7 - Fontes de crescimento da produção de leite - Brasil e principais países exportadores

\begin{tabular}{|c|c|c|c|c|c|c|c|c|c|}
\hline \multirow[b]{2}{*}{$\begin{array}{l}\text { Brasil e Unidades } \\
\text { da Federação }\end{array}$} & \multicolumn{2}{|c|}{$\begin{array}{c}\text { Produção } \\
\text { (milhões de It ou kg) }\end{array}$} & \multicolumn{2}{|c|}{$\begin{array}{l}\text { Vacas Ordenhadas } \\
\text { (1.000 cabeças) }\end{array}$} & \multicolumn{2}{|c|}{$\begin{array}{l}\text { Produtividade } \\
\text { Média } \\
\text { (It ou kg/vacas) }\end{array}$} & \multirow{2}{*}{$\begin{array}{c}\text { Variação } \\
\text { Produção }\end{array}$} & \multirow{2}{*}{$\begin{array}{c}\begin{array}{c}\text { Variação } \\
\text { Vacas }\end{array} \\
\text { \% }\end{array}$} & \multirow{2}{*}{$\begin{array}{c}\text { Variação } \\
\%\end{array}$} \\
\hline & 2001 & 2012 & 2001 & 2012 & 2001 & 2012 & & & \\
\hline Brasil & 20.510 & 32.304 & 18.194 & 22.804 & 1.127 & 1.417 & $57,51 \%$ & $25,34 \%$ & $25,67 \%$ \\
\hline EUA & 74.994 & 90.824 & 9.103 & 9.233 & 8.238 & 9.837 & $21,11 \%$ & $1,43 \%$ & $19,40 \%$ \\
\hline Argentina & 9.500 & 11.679 & 2.450 & 2.193 & 3.878 & 5.326 & $22,94 \%$ & $-10,49 \%$ & $37,34 \%$ \\
\hline Austrália & 10.864 & 9.811 & 2.281 & 1.650 & 4.763 & 5.946 & $-9,69 \%$ & $-27,66 \%$ & $24,84 \%$ \\
\hline Nova Zelândia & 13.162 & 20.567 & 3.557 & 5.018 & 3.700 & 4.099 & $56,26 \%$ & $41,07 \%$ & $10,76 \%$ \\
\hline EU & 130.069 & 139.000 & 25.747 & 23.052 & 5.052 & 6.030 & $6,87 \%$ & $-10,47 \%$ & $19,36 \%$ \\
\hline
\end{tabular}

Fonte: IBGE (Brasil) e USDA (demais países).

Por outro lado Argentina e União Europeia tiveram aumento de produção (22,94\% e 6,87\% respectivamente) com redução do tamanho do rebanho (-10,49\% e $-10,47 \%$ respectivamente). O aumento de produção foi provocado por ganhos de 
produtividade de $37,34 \%$ para a Argentina (a maior dentre os países) e de 19,36\% para a União Europeia.

A Austrália mostra uma produção declinante $(-9,69 \%)$ com redução do número de vacas ordenhadas $(-27,66 \%)$ e aumento de produtividade $(24,84 \%$ - terceira melhor dentre os países observados).

Por fim, a Tabela 8 mostra a produtividade média e marginal da Nova Zelândia, um país tradicionalmente exportador, com os indicadores do Brasil, Rio Grande do Sul e Região do COREDE Produção. Verifica-se que a produtividade média brasileira é muito baixa para padrões internacionais. No entanto, a dinâmica do crescimento do setor lácteo brasileiro mostra que em média a produtividade incremental é superior a produtividade média, revelando ganhos de eficiência do sistema produtivo setorial. Em termos regionais o desempenho do Rio Grande do Sul é superior a média brasileira, destacando-se a região do COREDE Produção que possui produtividade média e incremental superior à da nova Zelândia.

Tabela 8 - Produtividade média e marginal de regiões selecionadas - 2001 a 2012

\begin{tabular}{l|c|c|c}
\hline \multicolumn{1}{c|}{ Regiões } & $\begin{array}{c}\text { Produtividade média 2001 } \\
\text { (It ou kg)/vaca }\end{array}$ & $\begin{array}{c}\text { Produtividade Marginal } \\
\text { (It ou kg)/vaca }\end{array}$ & $\begin{array}{c}\text { Produtividade média } 2012 \\
\text { (It ou kg)/vaca }\end{array}$ \\
\hline Brasil & 1.127 & 2.559 & 1.417 \\
Nova Zelândia & 3.700 & 5.068 & 4.099 \\
Rio Grande do Sul & 1.845 & 5.851 & 2.670 \\
Produção & 2.620 & 8.070 & 4.533 \\
\hline
\end{tabular}

Fonte: tabelas anteriores

\section{Considerações finais}

Este artigo teve como objetivo elaborar uma perspectiva da cadeia láctea gaúcha enfocando o Corede Produção e verificar os fatores que explicam o aumento de produção em diferentes cortes regionais: país, maiores estados produtores de leite, regiões gaúchas e municípios do Corede Produção.

Verificou-se que a produtividade média do Brasil, em 2012 foi de apenas 1.417 litros/vaca/ano. O estado com maior produtividade é o Rio Grande do Sul com 2.670 litros/vaca/ano, e observando as regiões gaúchas, destaca-se a região do Corede Produção como a de maior volume de produção (10,22\% da produção estadual) e de maior produtividade (4.533 litros/vaca/ano). 
A produtividade média da região do Corede Produção é superior à média observada na Nova Zelândia (4.099 kg/vaca/ano), país de grande tradição na produção de leite. Dentre os municípios da região destaca-se o município de Casca que possui a maior produção municipal do estado e tem a terceira melhor produtividade do estado (5.400 litros/vaca).

Na média a produção de leite do Rio Grande do Sul aumentou 82,2\% entre 2001 e 2012 sendo explicado pelo aumento de 25,9\% do tamanho do rebanho de vacas ordenhadas e pelo aumento de $44,7 \%$ da produtividade. Já a região do Corede Produção aumentou a produção de leite em 166,65\% entre 2001 e 2012 sendo explicado pelo aumento de $54,1 \%$ do tamanho do rebanho de vacas ordenhadas e pelo aumento de $73,0 \%$ da produtividade. O crescimento da produção no estado do Rio Grande do Sul e da região da produção é classificado como intensivo, ou seja, os ganhos de produtividade são maiores que o aumento do tamanho do rebanho, possibilitando o aumento de produção com redução de custos unitários de produção.

Neste período, a produtividade marginal do Corede Produção alcançou 8.070 litros/vaca, superior à produtividade marginal do Rio Grande do Sul (5.851 litros/ vaca), do Paraná (4.468 litros/vaca), Pernambuco (3.446 litros/vaca) e Santa Catarina (3.424 litros/vaca). Quando a produtividade marginal é maior do que a produtividade média indica que a produção está crescendo com rendimentos crescentes sobre os insumos variáveis, sinalizando que os agentes produtivos devem avançar o nível de produção.

Interessante observar que o estado de São Paulo está reduzindo a produção total de leite mesmo sem ter alcançado a produtividade média brasileira e de estados mais produtivos, explicado pela lucratividade de culturas alternativas que competem por seus fatores de produção.

Quanto ao setor lácteo as importações mostram que a eficiência setorial como um todo ainda é vulnerável e, portanto existem necessidades de aprender sobre o processo de ajustamento estrutural, particularmente sobre a dinâmica do setor agrícola num contexto de globalização. Os processos de ajustamento estrutural têm colocado alguns países em desenvolvimento numa posição de explorar mais diretamente suas vantagens comparativas nacionais e regionais.

Anteriormente, os sistemas de mercado de alimentos trabalhavam dentro de estruturas paraestatais controladas e ineficientes em parte planejadas para trazer benefícios sociais máximos e não para determinar valor, suprindo os produtores de serviços e oportunidades de valor adicionado. Atualmente, sistemas de mercado competitivos e dinâmicos são reconhecidos como o principal meio para assegurar crescimento econômico ótimo. No momento em que os sistemas econômicos 
nacionais têm sido liberalizados e as tarifas de importação reduzidas, têm ocorrido deslocamentos de produção nacional, regional e internacional e as questões de competitividade estão se tornando de extrema importância.

É o que se verifica na marcha de produção leiteira dos últimos anos, com ganhos de produtividade em parte do território nacional alcançando países de desempenho exportador. Verifica-se que o mercado nacional é heterogêneo e, claro, as diferenças fazem parte do mundo real. É preciso difundir as novas tecnologias do setor, onde como observado anteriormente, no longo prazo, o deslocamento da escala da fazenda para uma tecnologia superior leva a firma a ter rendimentos crescentes de escala, chamados de externos à firma.

Dado a complexidade da cadeia produtiva do leite, deve-se avançar nos estudos sobre o setor, especificamente na pesquisa de campo junto aos produtores, de forma a verificar as demandas tecnológicas, financeiras e de infraestrutura dos agentes produtivos. 


\title{
Dynamics of the sources of growth of the Brazilian milk production between 2001 and 2012: a focus in production region - Rio Grande do Sul, Brazil
}

\begin{abstract}
The aim of this study was to analyze the sources of growth in milk production in different Brazilian geographic areas, focusing on the Production Region in the state of Rio Grande do Sul, in the period 2001-2012. It was observed that on average, Brazil, Rio Grande do Sul and Production Region, had an expansion of milk production $(57.5 \%, 82.2 \%$ and 166.6 $\%$, respectively) explained in more part by expansion of productivity $(25.7 \%, 44.7 \%$ and $73.0 \%$, respectively) than by increasing the number of milking cows $(25.3 \%, 25.9 \%$ and $54.1 \%$, respectively), with greater benefits to the Production Region, followed by the state of Rio Grande do Sul. The average productivity of Production Region (4533 liters / cow) and most of its municipalities are superior than average productivity of exporting countries as New Zealand (3,880 kg). Between 2001 and 2012 the marginal productivity of Rio Grande do Sul (5851 liters/cow) and Production Region (8070 liters /cow) were higher than average productivity of Argentina (5326 kg/cow) and the European Union (6030 kg/cow) signaling generating exportable surpluses with competitiveness.
\end{abstract}

Key words: Sources of growth, milk production, average and marginal productivity.

\section{Dinámica de las fuentes de crecimiento de la producción de leche brasileña entre 2001 y 2012: un enfoque en la región de planificación corede producción - Río Grande del Sur}

\section{Resumen}

El objetivo de este estudio fue analizar las fuentes de crecimiento de la producción de leche en diferentes espacios geográficos brasileños, enfocando la Región de la Producción, en el estado del Río Grande del Sur, en el periodo de 2001 a 2012. Se observó que en la media, lo Brasil, el estado del Río Grande del Sur y la Región de la Producción, tuvieron una expansión de la producción leche (del $57,5 \% ; 82,2 \%$ y 166,6\%, respectivamente) explicada en mayor parte por la expansión de la productividad (del 25,7\%; 44,7\%; y 73,0\%, respectivamente) del que por la expansión del número de vacas ordenhadas (del 25,3\%; 25,9\%; y 54,1\%, respectivamente) con ventajas mayores para la Región de la Producción, seguido por el estado del Río Grande del Sur. La productividad media de la Región de la Producción (4.533 litros/vaca) y de la mayoría de sus municipios son superiores la productividad de países exportadores como Nueva Zelanda (4.099 kg). Entre 2001 y 2012 la productividad marginal del Río Grande del Sur (5.851 litros/vaca) y de la Región de la Producción (8.070 litros/vaca) fueron superiores a la productividad media de la Argentina (5.326 kg) y de la Unión Europea $(6.030 \mathrm{~kg})$, respectivamente, señalizando la producción de generación de excedentes exportables con competitividad.

Palabras clave: Fuentes de crecimiento, producción de leche, productividad media y marginal. 


\section{Referências}

CARVALHO, M. P. et al. Cenários para o leite no Brasil em 2020. Juiz de Fora: Embrapa Gado de Leite, 2007.

FILGUEIRAS, G. C. et al. Fontes de crescimento da produção de pimenta-do-reino no estado do Pará no período de 1979 a 2001. In: CONGRESSO BRASILEIRO DE ECONOMIA E SOCIOLOGIA RURAL, XLII, 2004, Cuiabá - MT. CD-ROM.

FINAMORE, E. B. Leite: questão de competitividade. Agroanalysis (FGV), Rio de Janeiro, v. 19, p. 39-41, 1999.

FINAMORE, E, B.; MONTOYA, M. A. Estrutura produtiva da cadeia láctea gaúcha: perspectiva regional do Corede Nordeste. Passo Fundo: UPF Editora, 2008.

FILGUEIRAS, G. C. et al. Fontes de crescimento da produção de pimenta-do-reino no estado do Pará no período de 1979 a 2001. In: CONGRESSO BRASILEIRO DE ECONOMIA E SOCIOLOGIA RURAL, XLII, 2004, Cuiabá - MT.

GOMES, S. T. Produção de leite no Brasil, 1991. Disponível em: <http:// www.ufv.br/der>. Acesso em: 10 out. 2014.

GOMES, S. T. Diagnóstico da Pecuária Leiteira de Minas Gerais em 2005. Belo Horizonte: FAEMG, 2006.

IBGE (Instituto Brasileiro de Geografia e Estatística), resultados da Pesquisa Pecuária Municipal (PPM). Disponível em: <http:www.ibge.gov.br>. Acesso em: 10 out. 2014.

JANK, M. A. et al. Competitividade do sistema agroindustrial do leite. São Paulo: Cepea, USP, 2000.

SATO, K. Production functions and aggregation. North-holland publising company, Amsterdam, Oxford, 1975.

USDA (United States Departure of Agriculture). Resultados do Economic Research Service. Disponível em <http://www.usda.gov/>. Acesso em: 10 out. 2014.. 